\title{
Power Game: Position of the Dominant Actors in Public Assets Management of Forest and Wildlife Sectors
}

\author{
Dr. Wenceslaus Mselya Sobayi \\ Faculty of Arts and Social Sciences, University of Nottingham, Malaysia Campus
}

\begin{abstract}
This paper provides an understanding of the issues which emerged as a result of the prevailing power struggle to control agendas and resources that take place between actors in policy making process related to forest and wildlife management. The paper helps to learn the manner in which actors relate in the power game. The paper examines the way change in bureaucratic paradigm has affected other actors' interests and beliefs in designing as well as implementing policies for improving forest and wildlife management in Tanzania. The paper reveals that more reform efforts are needed to eradicate classical public administration bureaucratic paradigm and increase the power of local communities and private sector by fully adopting the new public management in Tanzania public sectors of forest and wildlife conservation. The paper suggests that current poor policy outcomes are the result of the strong beliefs and adherence by bureaucrats to the existing policy, legal and regulatory frames on one hand, and loss of other actors' interests and beliefs (i.e. local communities and the private sector interests and beliefs) into the current systems and processes which also include policy, legal and regulatory frames, on the other. The paper shows that the present policy, legal and regulatory frames collectively contradict and discourage participation of key actors in designing and implementing policies. The paper further indicates that local communities' and the private sector's ideas are without doubt weapons or strategic tools which can have political, social and economic influence, but unfortunately at the moment MNRT has not been able to make use of such weapons to improve the poor policy outcomes. Hence, paper suggests that the ideas which are needed to design and implement policies must serve the interests of the dominant actors (i.e. local communities and the private sector, according to Forest Policy 1998 and the Revised Wildlife Policy 2007) by strengthening their position in the power game of designing and implementing policies. Currently, the ideas which are being used in power game of designing and implementing policies are those coming from bureaucrats and development partners, thereby weakening the position of the local communities and private sector as dominant actors. The weak position of local communities and the private sector in the power game has led to the formulation and implementation of weak policy provisions and eventually produced poor policy outcomes. Therefore, paper further suggests that status quo of marginalisation of key actors in designing and implementing policies should and can be avoided. At the moment, bureaucrats may have designed policies, legislations and regulations that allows them to take more control over forest and wildlife resources. However, paper shows that local communities have more opportunities than the bureaucrats which increases their power to defy the laws and regulations introduced, such as preventing encroachments into the forest and wildlife reserves. Similarly, the private sector may choose to withhold their technical and financial prowess. Thus, MNRT should make use of the opportunities possessed by local communities and the private sector, as compared to current marginalisation. Additionally, MNRT should recognise that interaction and mutual trust are necessary in any established social system.
\end{abstract}

Keywords: Bureaucratic Paradigm, New Public Management, Classical Public Administration, Forest and Wildlife Management, Tanzania

DOI: $10.7176 / \mathrm{PPAR} / 10-10-09$

Publication date:October $31^{\text {st }} 2020$

\section{Introduction}

The bureaucratic paradigm is either a classical public administration manifested by ingrained and narrowlyfocused pattern of thought which involves misrepresentation and at worst, a demonstrable distortion of traditional thought that displays far more respect for law, politics, citizen and values, or the new public management, that is, newly customer-oriented managerialism and its variants (Lynn Jr 2001 p.144). Thus, bureaucratic paradigm is divided into either Classical Public Administration (CPA) or New Public Management (NPM) which was developed in 1980s. In NPM, focus is placed on public service institutions to be part of the effort to make the public service more efficient by using private sector management models (Polidano 1999 p.2). According to Gruening (2001 p.7) NPM is basically a paradigm which shifts emphasis from elites to the masses (i.e. the people). This is how the phrase, "public management" was derived.

In other respects, the actor-centred constructivism focuses on explaining power relations and the strategic behaviour of policy actors involved, and the way actors make use of their ideas, norms, interests and beliefs in public policy process (Saurugger 2013 p.898). Normally, economically rationalist thinking is brought into the analysis and linked to the use that actors make of those ideas, interests and beliefs (ibid).

The actor-centred constructivist theory introduces the socio-logical methods, concentrating on the study of 
individual actors or groups of actors, which help in understanding the power games (the power struggles for control of agendas and resources) that take place between actors in public policy (Saurugger 2013 p.898). The actorcentred constructivist theory particularly deals with two issues: the complexity of policy-making processes and legitimation issues (ibid).

\section{The design and implementation of public policy, philosophy and Tanzania experience}

Public policy is defined as a framework that allows the state to outline the proximate reasons for devoting attention to an issue and how the issue evolves from relative obscurity to something that needs to be discussed as a serious contender for legislation (Page 2005). Public policy originated as a product of the capitalist system in Germany during the transition from pre-industrial to industrial society as a response to emerging socialism (Moore 1967). It was a strategy aimed at solving discontentment in the working-class (Page 2005).

Policy can be conceptualised as either an action or intention. Based on this definition, we classify policy into two; policy intention and policy action.

According to Page (2005), policy intentions are mostly written principles which provide a general overview about how a particular public affair should be arranged or conducted. At a much higher level, it refers to a set of discrete principles known as ideology (ibid).

Therefore, ideology is also a policy, but from a political viewpoint, an ideology like socialism can generate sub-ideologies (under the term principles) which will be specific to a certain area like public ownership of assets, the role of a party in running state affairs including businesses, workers' rights and so on (Page 2005). Ideologies also encompass individual ideas such as Thatcherism, Reagonomics, New Public Management and "The third way" (ibid).

Freeden (2006) explains the relationship between ideology and policy. As for the former, it involves a view of the world, the problems surrounding it, a vision of how those problems can be solved and how a better future can be created (ibid).

Meanwhile, the later involves the practical steps taken to achieve a particular ideological vision (Freeden 2006). It would involve the passage of new laws, executive orders and so on depending on what the ideology seeks to achieve (ibid). On the other hand, policy actions can be manifested by the practices of officials (Page 2005). The way officials behave serves to interpret the decisions made and followed (ibid).

Moreover, there are measures in place such as legal instruments which can be considered as policies (Page 2005). Hence, practices are products of measures that seek to give effect to a policy (ibid). Policy is also considered as a science, and this type of science is termed as policy science which is defined as a social science dealing with the making of high-level policy for the government or business (Eneanya 2010). Policy science seeks to understand and solve problems ( $\mathrm{ibid}$ ). Whether those problems are local, regional, international or planetary, policy science provides an integrated and comprehensive set of procedures for addressing them in ways that help to clarify and secure the common interest of actors involved (Lynch 2013). Helping people make better decisions is the central objective of policy science, and the fundamental goal is to foster a common wealth of human dignity for all (ibid).

\section{Constructivism in public policy}

Constructivism refers to the assumption that social norms and frameworks on which reality is based are constructed and redefined through permanent interaction (Berger and Luckmann 1966). Actors' interests cannot be understood as deduced from a solely material structure, as rational choice approaches would argue (Elster 1989; Mueller 2003). Rational choice derives preferences exogenously by specifying properties (position, resources, etc.) across actors and how different values of properties imply different preferences (ibid).

Hence, constructivists assume that social, political and economic contexts structure these interests; thus, actors and structures are co-constituted - one of the central terms in constructivist research (Page 2005). In other words, the way we think about the world makes the world as we perceive it (ibid).

Thus, constructivists have a very different understanding of how interests change (Page 2005). They assume that interests change as agents alter their understanding of their changing world and recalculate their priorities (Be'land and Cox 2010). For materialists on the other hand, assume actors' interests evolve as changes in their environment alter their situation (Page 2005).

According to Saurugger (2013), the importance of this co-constitution of agents and structures is reflected in the opposition of two logics: logic of appropriateness and logic of consequentialism. The logic of appropriateness is a perspective that sees human action as being driven by rules of appropriate or exemplary behaviour, organised into institutions; and logic of consequentialism is a perspective that the moral value of human action is to be judged on its consequences rather than the action itself (in particular March and Olsen 1998; for a less constructivist and more sociological perspective, see March and Olsen 1984; 1989). Whereas the logic of consequentialism treats agents and structures as two distinct features that explain political processes (the goal of action is to maximise one's own interests and preferences), the logic of appropriateness allows for the conceptualising of this co- 
constitution of actors and structures (Saurugger 2013).

Rules are followed because they are seen as natural, rightful, expected, and legitimate (Saurugger 2013). Actors seek to fulfil the obligations encapsulated in a role, an identity, a membership in a political community or group, and the ethos, practices and expectations of its institutions (March and Olsen 2004). Thus, acting according to logic of appropriateness is more a question of behaving correctly in policy-making processes, in line with the criteria established by a society or a group, than maximising one's preferences (Ostrom 1999).

The logic of appropriateness refers to ideas (Be'land 2009), or, in other words to the 'collective understandings of social facts', as the primary source of political behaviour. These 'claims about descriptions of the world, causal relationships, or the normative legitimacy of certain actions' (Parsons 2002 p.48), influence policy development in three ways (Be'land 2009 p.702).

First, they help to construct the problems and issues that enter the policy agenda; second, they frame the basic assumptions that influence the content of reform proposals; finally, ideas can act as discursive tools that shape reform imperatives (Saurugger 2013). To what extent does this help us to better understand, on one hand, the issue of complexity, and on the other, the ambiguity of public policy making? Not paying attention to the embeddedness of actors in cognitive frames may obfuscate major aspects of policy-making (ibid).

Not only is it important that policy decisions and policy reforms have been taken, but also why the agents of policy processes sometimes do not react as expected (Saurugger 2013). Their rationality is embedded in specific cognitive frames that must be understood in order to make sense of, sometimes, ambiguous behaviour (ibid).

In other respects, Tanzania has various policies and legislations that have been used to manage public assets particularly forest and wildlife resources. To a large extent, these policies and legislations are to blame for the strife between colonial and post-colonial governments on one hand, and local population on the other who usually demand for free access to the forest resources for their survival (Mgaya 2017). Additionally, there has been a demand for increased involvement of local communities in designing and implementing policies particularly in wildlife management (Nelson et al 2007). In Tanzania, wildlife management is largely centralised, featuring large state-protected areas and strict control on resource use throughout the colonial and post-independence periods (ibid).

Tanzania is highly dependent on natural resources, the most important of which is land and other Common Pool Resources (CPRs) such as forests and those of wildlife which contribute nearly more than half of the Gross Domestic Product i.e. GDP (Shivji 2002). However, the creation of protected areas (national parks, forest reserves etc.) has resulted in the dispossession of resources from local communities (ibid).

Dispossession of CPRs (particularly those of forest and wildlife nature) is certainly perceived to be so because local communities have not been involved in the designing and implementing processes of creating protected areas and have not benefited from them (Shivji 2002). That dispossession has happened in the environment of state policies such as nationalisation (ibid).

Historically, for the past five decades, local people have been excluded from engaging in processes which could provide mutual benefit for the government and local communities in Tanzania (UNEP 2002). This sort of systemic marginalisation is responsible for the continued deterioration, deforestation and degradation of forests and the resources therein (Lokina and Robinson 2008).

Lokina and Robinson (2008) argue that, Ministry of Natural Resources and Tourism (MNRT) is oblivious of the needs and importance of forests to local communities that rely on the forests for fruits, vegetables, fuelwood, medicinal plants, incomes from activities such as beekeeping and butterfly farming and so on. They suggest that, recognising and attending to the needs of villagers would definitely encourage them to participate in managing local forests and subsequently reduce deforestation and forest degradation (ibid). Likewise, Shauri (1999) argues that, the MNRT continues to maintain state ownership and control of wildlife resources. The continued state ownership and control of wildlife resources shows the patron-client relationships that have made MNRT, the sole owner of wildlife resources; which sometimes makes MNRT and local community relations difficult (ibid).

In 1998, for the first time in Tanzania's history, the MNRT introduced the idea of local participation in forest policy; this was later incorporated into the subsequent Forest Act No. 14 of 2002 (Lokina and Robinson 2008). The introduction of Forest Policy 1998, was aimed at salvaging Tanzania's forests from abject deterioration and assisting the MNRT to manage country's forest land (ibid). Similarly, Wildlife Policy 2007 (RE) was introduced as a revised edition of Wildlife Policy 1998, which attempted to initiate the devolution of wildlife operations to local communities (MNRT 2007).

Thus, considering that Forest Policy 1998 and Wildlife Policy 2007 (RE) have brought for the first time the idea of participation of other actors in their implementation, the researcher seeks to examine the way change in bureaucratic paradigm in relation to these new developments brought about by the respective policies. This has prompted the research question, how has change in bureaucratic paradigm, affected other actors' interests and beliefs in designing as well as implementing policies for improving forest and wildlife management in Tanzania? 


\subsection{Study objective}

To examine the way change in bureaucratic paradigm has affected other actors' interests and beliefs in designing as well as implementing policies for improving forest and wildlife management in Tanzania.

\subsection{Research theory and model}

The theoretical framework which underpinning this research lies with Saurugger (2013) actor-centred constructivist theory and Ostrom (2005) model of Institutional Analysis and Development (IAD). The empirical data are therefore subjected to the assumptions and principles of respective theory and model in order to interpret them and explain the relationship that exists between bureaucratic paradigm and actors' interests and beliefs in designing as well as implementing policies for forest and wildlife conservation.

The theory and model provide an understanding of the issues which emerged as a result of the prevailing power struggle to control agendas and resources that take place between actors in policy making process related to forest and wildlife management in Tanzania. The theory and model help to examine the way actors relate in the power game.

\section{The Saurugger (2013) actor-centred constructivist theory}

According to Saurugger (2013 p.898), actor-centred constructivist theory focuses more on the power relations and the strategic behaviours of policy actors involved and the way actors make use of their ideas, norms, interests and beliefs in public policy process. Actor-centred constructivist theory introduces the socio-logical methods, concentrating on the study of individual actors or groups of actors, which help in understanding the power games (i.e. the power struggles for control of agendas and resources) that take place between actors in public policy (ibid). In order to understand the power relations which exists among actors involved in policy making, Saurugger (2013) actor-centred constructivist theory works by following the underlying assumptions that: the individual ideas, interests and beliefs of an actor are constructed and very important in defining the policy outcomes; the beliefs of actors usually guide their actions and sometimes perceived beliefs only rationalise strategies that can be chosen for other reasons; and the ideas are weapons or strategic tools which can have political, social and economic influence (Saurugger 2013 pp.896-900).

Meanwhile, in order to understand the power relations which exists among actors involved in policy making, the theory works by following the underlying principles that: actors must create broad coalitions around common strategies in order to achieve better policy outcomes; understanding of economic, political and social challenges, their interpretation and their analysis must emanate from cultural and ideal structures in which policy actors operate; and the ideas must serve the interest of the dominant actors by strengthening their position in the game (Saurugger 2013 p.897).

\section{The Ostrom (2005) model of Institutional Analysis and Development (IAD)}

Furthermore, the Institutional Analysis and Development (IAD) model developed by Elinor Ostrom, suggests that communities can contribute enormously in reducing the policy gap, once they have been entrusted to manage resources without government intervention. The model challenged the conventional wisdom about the need for government intervention over management of public resources in order to attain sustainability and benefit sharing (Ostrom 2005 p.219).

The IAD model was originally conceived in the 1980s by Elinor Ostrom, Nobel Prize winner in economics in 2009 , to study management of common resources such as forests and their governance by communities without state intervention. The model has been continually refined by Ostrom and other scholars over the last three decades. The model has been largely used in developing countries.

The IAD model has been applied to a variety of studies on how people collaborate and organise themselves across organisational and state boundaries to manage common resources such as those of forest and wildlife which often belonging to or affecting the whole of a community (Hess and Ostrom 2006; Hess 2006).

The Ostrom (2005) model of institutional analysis and development works as follows: in managing common resources, the underlying assumptions are; institutions are being considered as man-made systems within which individual choices are allowed to take place in order to achieve a particular outcome; interaction and mutual trust are necessary in any established social system; actors within a system can choose for themselves what type of outcome they wish to achieve; and the degree of power of an individual in a situation is usually affected by the government control (i.e. control of the resources) and opportunity (i.e. the chance offered by the situation). Thus, in mathematical language, the power is the function of the two variables of control and opportunity. In other words, power depends on the two (i.e. control and opportunity) and any change to the two will affect the power of an individual. Hence, the change in degree of control and opportunity should affect the power of an individual in a situation (Ostrom 2005 pp.50-55).

Meanwhile, in managing common resources, the model works by following the underlying principles that; interactions among actors must be guided by a set of rules in order to achieve an outcome i.e. principle of 
aggregation; there must be rewards or punishments in order to achieve an outcome i.e. pay-off principle; and each actor must be assigned a particular position, in other words, each must have a role to play in order to achieve the outcome i.e. position principle (Ostrom 2005 pp.193-207).

\subsection{Narratology of the Study}

A qualitative approach was found to be more appropriate in understanding how has change in bureaucratic paradigm, affected other actors' interests and beliefs in designing as well as implementing policies for improving forest and wildlife management in Tanzania? The preference given to qualitative approach over quantitative in this study was due to the fact that, quantification of policy effects in Tanzania has been difficult because of lack of reliable, consistent and comprehensive data in almost all sources of statistics (UNEP 2002).

In this study, interpretivism was chosen as the research philosophy. Additionally, a flexible research design was adopted and an interpretive case study was employed. Since the study was qualitative, semi-structured interviews and interactions were conducted. In establishing the sample size and choosing respondents and sampling technique, the sample size was 40 respondents and non-probability sampling technique was chosen, and technique used was purposive.

Data transcription was carried out by professional transcribers and later translated from Swahili to English by independent translators to ensure limited chance of subjectivity and bias in the study. Data transcribed and translated were subsequently entered into NVivo software where they were auto-coded and analysed until themes were identified. After these themes were identified, each theme was further analysed and interpreted by using analytical techniques of Content analysis and Narrative analysis.

The logic behind data interpretation in narrative analysis is to translate the stories of respondent's experiences into a narrative form. Narrative form is said to be produced, once a coherent story from data has been constructed. In short, through the use of narrative analysis, the author provides new and interpreted narrative which has a different message, embedded with unbiased personal opinion when being constructed (Segel and Heer 2010).

\section{The bureaucratic paradigm change and its effects on other actors' interests and beliefs in designing and implementing policies for forest and wildlife management}

There are changes in public service delivery after the Government of Tanzania chose to adopt free enterprise system from the old socialist system guided by the Arusha Declaration. The change of economic system has also demanded public sector reform in policy management and particularly change in bureaucratic paradigm.

However, in spite of the change of economic system, CPA continues to exist among bureaucrats, which makes the process for public sector reform relatively static. There is a discrepancy between the NPM introduced in mid 1980s' in Tanzania bureaucracy and the actual situation resulting from bureaucrats' admiration of the CPA. This discrepancy is hindering successful policy reforms in public sector.

There have been various reforms in Tanzanian bureaucracy such as Public Service Reform Program (PSRP) funded by the World Bank, which seeks to improve accountability, transparency and resource management. However, the reform efforts have not been able to bring significant change into the old bureaucratic paradigm of CPA. The decision by bureaucrats to continue embracing CPA in spite of changes from socialism to free enterprise has adversely affected participation of local communities and the private sector in designing and implementing policies for forest and wildlife management.

When it comes to the way these actors (i.e. local communities and the private sector) participate in policy design and implementation, there is actually minimal involvement. Study shows majority of bureaucrats continue to believe in the socialist approach during design and implementation of public policies. The bureaucrats continue to formulate and implement policies, legislations, regulations and rules which do not encourage cooperation with outside actors.

A case in point, is the formulation of Wildlife Policy 1998 which continued to maintain legal and institutional status quo, that jeopardise the relationship between the state on one hand, and local communities as well as private sector on the other. The CPA in wildlife conservation has made MNRT less responsive to the calls of both local communities and the private sector.

The CPA in wildlife conservation has caused MNRT to employ militaristic strategies in conserving the wildlife resources, which subsequently led to more conflicts than harmonies between the bureaucracy on one hand, and mainly the local communities on the other. This particular situation has made TAWA and TANAPA to be more of an armed paramilitary organisations focusing in strengthening law enforcement by conducting anti-poaching patrols, investigating and prosecuting wildlife cases.

Likewise, when it comes to the role of the private sector, Non-Governmental Organisations (NGOs) and the general public (i.e. local communities in particular), Wildlife Policy 1998 erroneously suggesting that society exists to serve the Government, not the other way round. The Wildlife Policy 1998 appeals to other actors (i.e. private sector, NGOs and the local communities) "...to support government efforts" in the conservation and management of wildlife resources" (MNRT 1998b pp. 29-30). It also categorically describes that "the role of local 
and international NGOs is to support the Government, financially and technically at all levels, in the conservation and management of wildlife resources" (ibid).

Study indicates that often times, private sector is mainly involved in forest and wildlife management when it is required to provide technical and financial support to the Government, and not in actual process of policy design, development, implementation or revision. Normally, private sector is more of the recipient of government directives.

The contribution of the private sector in forest and wildlife management is vital for new and quality policy inputs which could improve related policies and the entire forest and wildlife management. The participation of private sector could help to obtain alternative views of private sector during policy design and avoid many practical challenges which erupt when both policies are implemented. Additionally, study shows that private sector has better technical and financial capabilities needed in forest and wildlife management.

The contribution of private sector and NGOs in policy designing, can be seen when preparing the policy briefs. Policy briefs are usually expected to feed into policy formulation, implementation and review processes. When preparing policy briefs, NGOs normally involve government officials. There is a particular policy brief which was prepared to look at the viability of Wildlife Management Areas (WMAs) whereby representatives of TANAPA and Ngorongoro Conservation Area Authority (NCAA) took part in its formulation. This particular arrangement of involving government officials usually helps to provide information to the Government on what should be expected in a forthcoming policy brief.

The result of this policy brief on viability of WMAs is expected to be seen in the next policy review process. Moreover, Community Wildlife Management Areas Consortium (CWMAC) which is the apex body of WMAs has prepared a policy brief which indicates some shortfalls in Wildlife Policy 2007 (RE), as the same does not address some of the key challenges encountered in WMAs. Meanwhile, study shows that MNRT is expected to convene stakeholders' meetings and receive inputs via these particular policy briefs on WMAs, which would feed into the next policy review of Wildlife Policy 2007 (RE).

Ecologically, WMA allows animals to migrate from one protected area to another, and wildlife operations within a particular WMA need to be financially supported so as to provide benefits to local communities. However, study shows that many WMAs face financial difficulties. Only few WMAs, for example, Ikona WMA in Serengeti district generates more funds than funds collected by Serengeti district council through various sources of income. Such an achievement is attributed to the investment agreement entered between local communities and the investor.

Actually, Ikona WMA is now amongst the few WMAs that generates a lot of revenue in Tanzania. It was formed by five local communities that decided to enter into an investment agreement with Grumeti Reserve Ltd, an eco-tourism company which established a resort within Ikona WMA and remits an agreed percentage of its revenue to Ikona WMA. That is what constitutes the success story of Ikona WMA. In such a case, the Government should allow the private sector to assume a more active and productive role in designing and implementing forest and wildlife conservation policies.

On the other hand, there have been other setbacks in policy implementation, particularly on coordinating NGOs involved in forest and wildlife management. In fact, there is lack of coordination between MNRT and NGOs. Many NGOs that operate in forest and wildlife sectors are not registered or recognised by MNRT. In other words, MNRT is unaware of the existence of many NGOs that operate within forest and wildlife industries. Eventually, these NGOs receive funds from development partners and start implementing forest and wildlife operations without the knowledge of the ministry responsible, i.e. MNRT.

The lack of proper coordination and cooperation between MNRT and NGOs, has resulted in duplication of efforts in forest and wildlife management. Often times, MNRT implement similar activities to those already being carried out by particular NGOs or other public bodies.

For example, lack of coordination and cooperation is evident, as there are NGOs reportedly to be registered to conduct similar institutional functions as combating wildlife crimes, such as Multi-Agency Task Team (MATT) and National and Transnational Serious Crimes Investigation Unit (NTSCIU). Meanwhile, there is TAWA which was established by MNRT in 2015 to similarly combating wildlife crimes. Furthermore, there are already other public authorities such as TANAPA and NCAA conducting similar functions, arguably each wildlife authority has been assigned a specific operational area i.e. either operates in game reserves or national parks, but these wildlife authorities have always been colliding in terms of their overlapping institutional functions.

Study further indicates that lack of proper coordination between MNRT and NGOs has also led to a situation where, other NGOs participate in international fora without the knowledge of MNRT and speak out on critical issues of forest and wildlife Management in Tanzania. Moreover, it occurs in some international meetings where NGOs speak contrary to the government's positions which show that NGOs are challenging positions taken by the Government on matters of forest and wildlife conservation.

Notwithstanding, usually NGOs are described as the second arm of the government and always support Government in areas where Government cannot reach. Generally, in forest and wildlife management, NGOs have provided enormous contributions. For example, the contribution of TFCG to forest management in Tanzania is 
commendable.

Study shows that contribution of private sector to forest and wildlife management cannot be overemphasised. The private sector has been supporting some of the key operations in forest and wildlife management such as combating wildlife trafficking, animal poaching and building capacity of government institutions. Additionally, the private sector has been contributing in policy debates such as the ones which seek to improve the existing Wildlife Policy 2007 (RE) for better policy outcomes.

The private sector has been providing financial assistance needed to strengthen relevant government institutions and even NGOs that operate in forest and wildlife management. Development partners have been mostly working with private sector to assist various NGOs under the arrangement of what is described as landscape partnership in forest and wildlife management. Landscape partners are local NGOs working closely to bring an integrated approach that would help in designing and implementing policies for forest and wildlife management. The landscape partners have enormous contribution to forest and wildlife management, and some of them are: TNC (The Nature Conservancy) based in the Northern Zone; Wildlife Conservation Society which operates in the Southern Zone particularly at Ruaha; and the Jane Goodall Institute (JGI) found in Western Zone.

The private sector (through NGOs) has also been taking other steps to improving forest and wildlife management. For example, TNRF (Tanzania Natural Resource Forum) is proposing some policy changes into Wildlife Policy 2007 (RE). Additionally, study shows that private sector has been assisting other NGOs such as, STEP (Southern Tanzanian Elephant Project) in working on ways to combat elephant poaching. Also, there is PAMS Foundation (for the Ruvuma Elephant Project) which works on training Village Game Scouts (VGS) to combat trafficking and poaching of wildlife resources.

Other NGOs are the African Wildlife Foundation (AWF) works on training canine dogs such as German shepherds used for detecting illegal trafficking of wildlife resources in harbours and airports. The Community Wildlife Management Areas Consortium (CWMAC), is a consortium of WMAs which operates as the apex body that brings together WMAs.

Another NGO which obtains assistance from the private sector is Lawyers' Environmental Action Team (LEAT), an environmental law organisation in Tanzania established to ensure sustainability in managing environmental and natural resources by analysing contradicting laws which cut across, such as Land Act, Wildlife Conservation Act, Energy Act etc. LEAT aids in identifying conflicting areas and providing advice on harmonisation of the same.

TRAFFIC is another NGO which deals with monitoring of legal cases related to wildlife management and implementation of judicial rulings. TRAFFIC deals with legal cases by following up on as many legal cases which lack adequate legal representation and they also strive to ensure that the verdicts offered by the judiciary are not lenient.

TRAFFIC is aiming at increasing awareness of the judiciary branch so that when incidents of illegal hunting of wildlife animal are reported and filed in court, the verdict would be expected to be close or equal to the extent of losses of wildlife resource. TRAFFIC provides training and expertise on how to deal with wildlife crimes.

The private sector has been receiving much of the financial and technical support from development partners. As earlier described, development partners has been supporting the private sector in designing and implementing forest and wildlife operations. The private sector is the leading actor in forest and wildlife management in Scandinavian Europe. This explains why Nordic countries choose to have more interactions and trust with the private sector including NGOs in Tanzania. Yet, study indicates that MNRT has minimal interactions and trust with the private sector and local communities as well. Increased interactions and trust are crucial for achieving the desired policy outcomes.

\section{The position of local communities and the private sector in the power game of designing and implementing policies for forest and wildlife management}

Study reveals that the position of local communities and private sector in the power game of designing and implementing policies for forest and wildlife management is weak. The study shows that the weak position of local communities and the private sector in the power game has contributed to prevalence of poor policy outcomes.

The study suggests that reform efforts should continue, to ensure that the old bureaucratic paradigm (i.e. classical public administration) is actually eliminated and paves the way for NPM which would elevate the position of other actors particularly local communities and private sector, and eventually improve forest and wildlife conservation. The study indicates that by fully adopting and implementing NPM, the interests and beliefs of dominant actors in systems and processes of designing and implementing policies for forest and wildlife management will significantly increase. The current poor policy outcomes are the result of low interests and beliefs of the dominant actors (i.e. local communities and private sector) into the existing systems and processes which include policy, legal and regulatory frames. The study shows that the existing policy, legal and regulatory frames collectively discourage cooperation among actors in designing and implementing policies, and also encourage marginalisation of local communities and the private sector. 
However, study indicates that forest policy 1998 and wildlife policies (RE) 2007 recognise local communities and the private sector as the dominant actors in forest and wildlife conservation. Yet, ideas of local communities and the private sectors are not being considered when designing and implementing policies for forest and wildlife management.

The study shows that local communities' and the private sector's ideas are without doubt weapons or strategic tools which can have political, social and economic influence, but unfortunately at the moment MNRT has not been able to make use of such weapons to improve the poor policy outcomes. The study further indicates that the ideas which are needed to design and implement policies must serve the interest of the dominant actors (i.e. local communities and the private sector) by strengthening their position in the power game. However, the ideas which are being used in power game of designing and implementing policies are those coming from bureaucrats and development partners, thereby weakening the position of the local communities and private sector as dominant actors.

Thus, study suggests that the minimal interests and beliefs of dominant actors in systems and processes of policy designing and implementation is primarily caused by the presence of CPA bureaucratic paradigm which has contributed to poor policy outcomes. The existing policies of forest and wildlife management are being designed and implemented without enough consultation and adequate consideration of the interests of dominant actors which could enable bureaucrats to understand the underlying issues which need to be addressed into the respective policies and subsequently improve policy outcomes

The Forest Policy 1998 and Wildlife Policy 2007 (RE) advocate dominance of local communities and the private sector in forest and wildlife management. Hence, study suggests that high interests and beliefs of dominant actors into the systems and processes involved in policy designing and implementation is of paramount importance.

The study further suggests that the ideas coming from local communities and private sector once have being validated, they can improve the existing policy outcomes. At the moment the ideas that control and run the game of forest and wildlife management actually serve the interests of bureaucrats and development partners such as better forest and wildlife conservation while ignoring the livelihoods and other vulnerability issues of local communities.

The study shows that bureaucrats use their ideas to design and implement policies which continue to support classical public administration in spite of changes from socialism to free enterprise. Meanwhile development partners protect their interests particularly of increasing the carbon stock, by using their funds and technologies to influence policies for better forest and wildlife conservation. The development partners have been financing and providing technologies to landscape partners to enable preparation of various policy briefs which feed into the existing policies as earlier described, while leaving local communities in weaker position, which adversely affects them in participating and contributing to the designing and/or implementing the systems and processes involved.

Therefore, study suggests that status quo of marginalisation of key actors in designing and implementing policies should and can be avoided. At the moment, bureaucrats may have designed policies, legislations and regulations that allows them to take more control over forest and wildlife resources. However, study shows that local communities have more opportunities than the bureaucrats which increases their power to defy the laws and regulations introduced, such as preventing encroachments into the forest and wildlife reserves. Similarly, the private sector may choose to withhold their technical and financial prowess. Thus, MNRT should make use of the opportunities possessed by local communities and the private sector, as compared to current marginalisation.

\section{Conclusion}

This paper examines the way change in bureaucratic paradigm has affected other actors' interests and beliefs in designing as well as implementing policies for improving forest and wildlife management in Tanzania. It is revealed that more reform efforts are needed to eradicate classical public administration bureaucratic paradigm and increase the power of local communities and private sector by fully adopting the new public management in Tanzania public sector particularly in forest and wildlife management.

The paper suggests that current poor policy outcomes are the result of the strong belief and adherence by bureaucrats to the existing policy, legal and regulatory frames on one hand, and loss of other actors' interest and beliefs (i.e. local communities and the private sector interests and beliefs) into the existing systems and processes which also include policy, legal and regulatory frames, on the other. The paper shows that the existing policy, legal and regulatory frames collectively contradict and discourage participation of key actors in designing and implementing policies. The paper further indicates that local communities' and the private sector's ideas are without doubt weapons or strategic tools which can have political, social and economic influence, but unfortunately at the moment MNRT has not been able to make use of such weapons to improve poor policy outcomes in forest and wildlife management. Hence, MNRT should recognise that interaction and mutual trust are necessary in any established social system.

Therefore, paper concludes by suggesting that the ideas which are needed to design and implement policies must serve the interest of the dominant actors (i.e. local communities and the private sector, according to Forest 
Policy 1998 and Revised Wildlife Policy 2007) by strengthening their position in the power game of designing and implementing policies. Currently, the ideas which are being used in power game of designing and implementing policies are those coming from bureaucrats and development partners, thereby weakening the position of the local communities and private sector as dominant actors. The weak position of local communities and the private sector in the power game has led to the formulation and implementation of weak policy provisions and eventually produced poor policy outcomes in forest and wildlife management.

\section{References}

Be'land, D (2009) Ideas, institutions, and policy change, Journal of European Public Policy, Vol. 16 (5), pp. 701 $-718$

Be'land, D and Cox, RH (eds.) (2010) Ideas and Politics in Social Science Research, New York, NY: Oxford University Press

Berger, P and Luckmann, T (1966), The Social Construction of Reality, Garden City, NY: Doubleday and Company Inc.

Elster, J (1989) Nuts and Bolts for the Social Sciences, Cambridge, MA: Cambridge University Press

Eneanya, AN (2010) Public Policy Analysis, National Open University of Nigeria

Freeden, M (2006) Ideology and Political Theory, Journal of Political Ideologies, Vol. 11 (1): pp. 03 - 22

Gruening, G (2001) Origins and theoretical basis of New Public Management, International Public Management Journal, Vol. 4 (1): pp. 1 -25

Lokina, RB and Robinson, EJZ (2008) Determinants of Successful Participatory Forest Management in Tanzania, Environment for Development in Tanzania (EfDT), Department of Economics, University of Dar Es Salaam, Tanzania

Lynn Jr LE (2001) The Myth of the Bureaucratic Paradigm: What Traditional Public Administration Really Stood For, Vol 16 (2) Journal of Public Administration Review

March, JG and Olsen JP (1984) The new institutionalism: Organisational factors in political life, American Political Science Review, Vol. 78 (3): pp. 734 - 749

March, JG and Olsen JP (1989) Rediscovering Institutions, New York, NY: Free Press

March, JG and Olsen JP (1998) The institutional dynamics of international political order, International Organisation, Vol. 52 (4): pp. $943-969$

Mgaya, E (2017) Forest and Forestry in Tanzania: Changes and Continuities in Policies and Practices from Colonial Times to the Present, Journal of the Geographical Association of Tanzania, Vol. 36 (2): pp. 45 - 58

Ministry of Natural Resources and Tourism (MNRT), (1998b) The Wildlife Policy of Tanzania, Dar es salaam, Tanzania

Ministry of Natural Resources and Tourism (MNRT), (2007) The Wildlife Policy of Tanzania, The Government Printer, Dar es salaam

Moore, B (1967) Social Origins of Dictatorship and Democracy: Lord and Peasant in the making of the modern world, London: Allen Lane, the Penguin Press.

Mueller, DC (2003) Public Choice III, Cambridge, MA:Cambridge University Press

Nelson, F, Nshala R and Rodgers WA (2007) The Evolution and Reform of Tanzanian Wildlife Management, Conservation and Society, Vol. 5 (2): pp. 232 - 261

Ostrom, E (1999) Institutional rational choice: An assessment of the institutional analysis and development framework, in a P.A Sabatier (ed), Theories of the Policy Process, Boulder, CO: Westview Press, pp. 35 - 71

Ostrom, E (2005) Understanding Institutional Diversity, Princeton, NJ: Princeton University Press

Page, EC (2005) Producing Public Policy, Oxford University Press

Parsons, C (2002) Showing ideas as causes: The origins of the European Union, International Organisation, Vol. 55 (1): pp. $47-84$

Polidano, C (1999) The new public management in developing countries, Institute for Development Policy and Management, University of Manchester

Saurugger, S (2013) Constructivism and public policy approaches in the EU: from ideas to power games, Journal of European Public Policy

Segel, E and Heer, J (2010) Narrative Visualisation: Telling Stories with Data, Stanford University, Stanford

Shauri, V (1999) The new wildlife policy in Tanzania: Old Wine in a New Bottle? Lawyers' Environmental Action Team (LEAT): pp. 02-09

Shivji, IG (2002) Village Governance and Common Pool Resources in Tanzania, Report to DFID - Natural Resources Systems Programme Semi-Arid Production System

UNEP, (2002) Integrated Assessment of Trade Liberalisation and Trade - Related Policies: UNEP Country Projects - Round II; A synthesis report, United Nations, New York and Geneva 